\title{
Probabilistic Modelling of Renewable Generation to Account for Uncertainties in Interconnection Studies
}

Running heads: Probabilistic Modelling of Renewables in Interconnection Studies

Authors: A. Garry ${ }^{1}$, M.C. Alvarez-Herault ${ }^{1}$, F. Cadoux ${ }^{1}$, N. Hadjsaid ${ }^{1}$

1 Univ. Grenoble Alpes, CNRS, Grenoble INP*, G2Elab, 38000 Grenoble, France

*Institute of Engineering Univ. Grenoble Alpes

Corresponding author: M.C. Alvarez-Herault, marie-cecile.alvarez@g2elab.grenoble-inp.fr

\section{$\underline{\text { Abstract }}$}

The development of renewable generation connected to the distribution network can create over-voltage or over-current situations leading to expensive upgrades of the network. Solutions such as production curtailment could avoid these expenditures, but in order to take full advantage of these new solutions, one must first appropriately model the statistical behaviour of loads and generation over several years with a high level of uncertainties. This paper performs a statistical analysis on 4254 real-world generation time series that run over about two years, with a ten-minute time step, for four different types of generation technologies. This large dataset was made available thanks to a partnership with the major French DSO, Enedis. The objective is to develop probabilistic models of the power output for each type of generator and also of the statistical dependency between two generators and between generation and load and to apply them on an interconnection case study.

Keywords: Probabilistic production modelling, Interconnection studies, Production curtailment, Uncertainties.

\section{Introduction}

\section{I.1. The Necessity of Modelling the Distributed Generation Productions for Interconnection Studies}

One of the roles of the Distribution System Operators (DSOs) is to expand the Distribution Network (DN) so as to remain within the voltage and current limits. Based on the available customer information, the DSOs find the best trade-off between investments and a desired service quality. The effect of a few situations with high consumption is tested and referred to as "maximal" consumption, although they are more likely thresholds with a low risk. The installed capacity of DGs, most importantly wind and solar, has increased steadily in recent years, leading to some concerns about the requirement for potentially heavy network investments ${ }^{1}$. Then, the DSOs have to make interconnection studies in order to make sure that there is no voltage or current violation in the case of maximal production and minimal consumption ${ }^{2}$. Instead of upgrading the network more and more as new DGs appear, alternative solutions are being investigated. For example, generation curtailment ${ }^{3}$ could avoid the need for reinforcement if the producer were to accept a reduction of its power output when the network needed it. But the economic benefits of these solutions depend on four main criteria: the type of constraint (over-current or over-voltage), its magnitude, its occurrence, and the business model of these alternative solutions. For example, if the interconnection of a producer creates over-voltage in the network during most of the year, then reinforcing the lines might be cheaper 
than compensating the producer for the energy curtailed. Then it is important to estimate (e.g. through their mean value and standard deviation) the behaviour of various statistical indicators, such as the amount of energy to be curtailed to prevent a particular constraint. Fortunately, this does not require the exact power generation and load to be forecasted over the long term, which would be an impossible task; what is needed is to assess the joint probability distribution of the load and of various types of generators (with similar or different technology types). In other words, the questions are: Are the times when various generators are producing near their maximal output synchronized? If they are, is there also synchronization with times of low load? And how much energy will have to be curtailed at these times in order to prevent the occurrence of particular network congestion? Such information, in the form of quantitative statistical indicators, is required for the evaluation of the economic interest of alternative solutions in interconnection studies.

\section{I.2. Literature Review}

In the literature, a huge number of papers propose methodologies and tools to integrate DGs into the expansion decision process of the DN. But most of them have a deterministic approach, as summarized by Keane and $\mathrm{al}^{4}$. The necessity of having stochastic approach rather than a traditional "peak" approach is highlighted by You and al. ${ }^{5}$. In Hemmati and al.'s study 6 , uncertainties in load and prices are considered but DGs are integrated only on the basis of the extreme case of maximal production, with no uncertainties and with the strong assumption that the DSO owns and operates the production. In Borges and al.'s work ${ }^{7}$, uncertainties in DGs are integrated through a nine-scenario approach, but the type of generation and the temporal effect are not accounted for. Considering the papers focusing on modelling the behaviour of producers in the future for a given application, two main approaches can be found. The first one consists in a functional description of the generators. The producer is precisely modelled and the production is assumed based on the information of several variables such as the wind or the solar irradiance. The amount of data required is huge and these data are not necessarily available to the DSO, which usually has access to little information about the technical details of individual decentralized generators. For example, three years of wind-speed historical data are converted into output powers following a given model of the wind generator by Nassar and al. ${ }^{8}$. Then four seasons are defined and the Johnson SB Probability Density Function (PDF) is fitted to them to model the wind power output and validated using statistical tests. The same approach is used to model the PDF of the PV production based on five years of irradiance data. In Karimi and al.'s paper', the wind speed is modelled with the Rayleigh rule scaled with the mean value speed of the studied site. The power of the generator is then computed based on a model of the wind generator. The given wind speed and power probabilities are used to compute the final $\mathrm{PDF}$ of the wind generator.

The second approach consists in estimating statistically the power injected in the network by modelling the output power under the condition of some measured inputs; in this case, the DSO does not need to know any technical details about the individual generators but needs historical data about their inputs (e.g. wind speed) and their output (electrical power). In many studies, the authors assume that the empirical law obtained from a few real historical power measurements is a good approximation of the real law. This approach is simpler to implement by the DSO compared to the first one, which is nevertheless more complete. For example, Kane and al. ${ }^{3}$ studies the evaluation of the production curtailment and Karimi and al. ${ }^{10}$ proposes a coordinated control of several DGs. Even though the models are interesting, they are not 
validated on a significant set of data to be generalizable such as in Fan and al.'s paper ${ }^{11}$, where the authors propose a probabilistic model of PV generation but only validate it on a unique time series.

Another important aspect is modelling the dependency between generators (of the same types or not) and also between generators and load. Some authors have studied this question. For example, without giving much detail, Faghihi and al. ${ }^{12}$ state that both wind productions and loads are correlated with themselves but not with each other. The CHP is independent from another CHP and from wind and loads. Finally as hydraulic and PV producers are marginal, they are represented by a constant power. Haghi and al. ${ }^{13}$ propose to model the dependency between wind and PV using Archimedean copulas based on some wind and solar irradiance measurements and real daily loads. Rankovic and al. ${ }^{14}$ and Vidovic and al. ${ }^{15}$ use a basic correlation indicator computed on pseudo measurements, which are clustered using Artificial Neural Networks. First, the correlation coefficient is basic and the number of clusters has an impact on the conclusions of dependency relation. Torres and al. ${ }^{16}$ only search for linear correlation in a very few data leading to questionable conclusions. Finally, Villanueva and al. ${ }^{17}$ 's paper, the dependency is considered as an input variable of a power flow algorithm. They present a methodology based on Monte Carlo simulation to generate data with several level of uncertainties.

\section{I.3. Contributions}

The main limitation of what we found in the literature is the dataset used for validation. Some studies used models that were not built on real power output data. The latter contain complex additional events such as outages (planned or unplanned), which are not usually captured by the theoretical models. Some other studies do use real historical data, but the datasets are usually limited and contain too few measurements to generalize the results. Also, to the best of our knowledge, no statistical model is currently available in the literature for CHP and hydraulic productions and their dependency on the other types of productions and loads.

In this paper, we study a significant set of French data consisting of 4254 time series of 10-minute production curves for wind, photovoltaic, hydraulic, and co-generation. These generators are connected to 1410 High Voltage (HV)/Medium Voltage (MV) substations throughout the country. The data were gathered over the years 2012 and 2013. This large dataset enabled us to carry out a deep statistical analysis and to propose probabilistic models for DG interconnection studies. Different models of dependency are explained and studied. In the last section of this paper, the results are used in a case study: a quadratic probabilistic load flow is run on a distribution feeder to which PV production will be connected. The occurrence of a risk of over-voltage leads the DSO to study the alternative between generation curtailment and reinforcement.

The paper is structured as follows: in Section II the general approach is explained, giving the statistical concepts and tools used to define the seasons and models for the four types of production. In Section III, the methodology is applied to French data and a real French distribution feeder. Finally, Section IV presents the conclusion and perspectives of the work. 


\section{Distributed Generation Modelling Methodology}

\section{II.1. General Algorithm Description}

The methodology depicted in Fig. 1 is applied to our dataset. For each type of generation $\mathrm{i}$ ( $\mathrm{i}=$ 1:4, 1 for cogeneration, 2 for wind, 3 for hydraulic, and 4 for CHP), a set of $n_{i}$ time series production curves over $y_{i}$ years are studied. First, a statistical analysis (step 1) of the generation per type is made so as to identify seasons where the production can be modelled by a unique statistical law. This law is defined by the Mean Cumulative Distribution Function (MCDF) (step 2). Then different dependency models are studied (step 3) so as to provide a table giving the dependency models as a function of the type of production, the loads, and the seasons when it is possible. This model of dependency defines the mathematical rules (sum and product, for example) that will be applied in interconnection studies. These results are applied an interconnection case study to show why having such models is of interest. The different steps are explained in detail in this section.

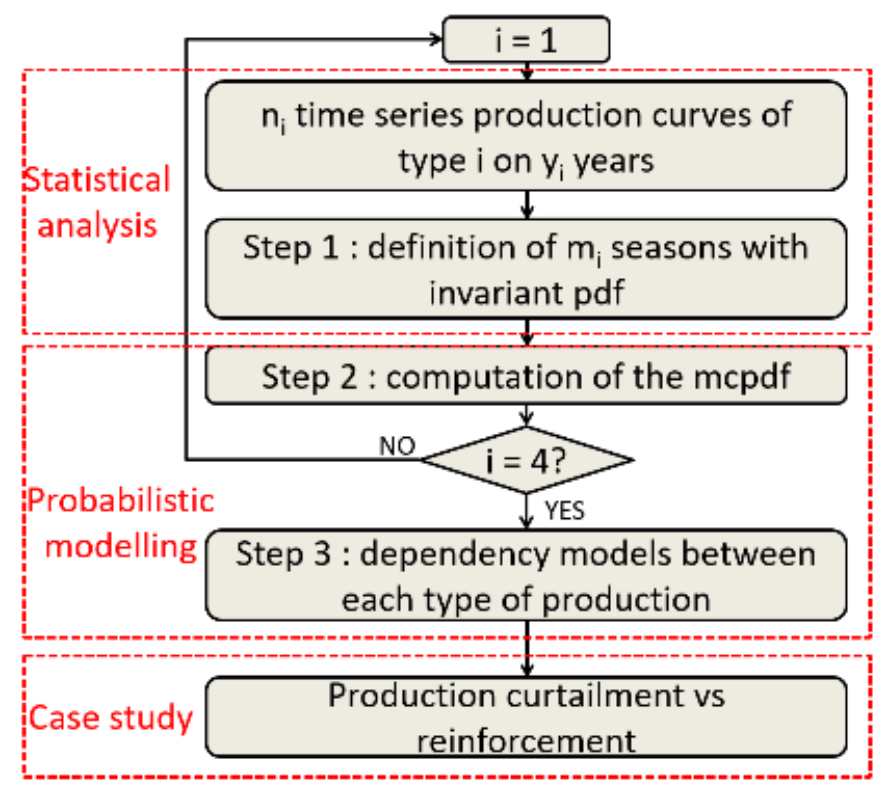

Fig.1 General methodology

\section{II.2. Step 2: Definition of Seasons per Type of Production}

It has been assumed that each producer of the same type follows the same PDF with a scale factor depending on the installed capacity. This strong hypothesis has been validated with the available measurements. In this step, a statistical analysis of historical measurements aims at defining the "seasons" for each of the four generation technologies, with a season being defined as a period of the year where the generator can be modelled by a unique Cumulative Distribution Function (CDF).

\section{II.2.1. Metrics Used}

\section{II.2.1.1. Metrics Used to Split the Year into Seasons}

One or several of the following metrics are used for defining the seasons chosen in this paper for the four types of generation technologies. The numeric results are provided in Section IIIB. 
- The output power $\left(\mathrm{P}_{\mathrm{i}}\right)$ at each step time for a year for production $\mathrm{i}$ expressed as a percentage of the maximal annual production $\mathrm{P}_{\max }(\mathrm{i})$ ( $\mathrm{i}=\mathrm{C}$ for $\mathrm{CHP}, \mathrm{H}$ for hydraulic, $\mathrm{W}$ for wind, and $\mathrm{P}$ for PV);

- The aggregated production $\left(\mathrm{P}_{\mathrm{ci}}\right)$ : the sum of all the productions of type $\mathrm{i}$ for each step time expressed as a percentage of the maximal aggregated annual production $\mathrm{P}_{\mathrm{cmax}}(\mathrm{i})$;

- The hourly (or monthly) mean production factor, $F_{i m H}$ (or $F_{i m M}$ ), given by Equation 1, and the 10 and $90 \%$ quantiles: the ratio between the energy produced during one hour (or one month) and the energy produced if the production was at 100\% during the whole of the hour (or month).

$$
F_{i m H}(h)=\frac{\sum_{6 h-5}^{6 h} P_{i}^{\prime}(h)}{6 P_{\max }(i)} \& F_{i m M}(m)=\frac{\sum_{i_{s}}^{i_{e}} P_{i^{\prime}}(m)}{6 P_{\max }(i)}
$$

where:

- $\mathrm{P}^{\prime}{ }_{\mathrm{i}}: \mathrm{P}_{\mathrm{i}}$ or $\mathrm{P}_{\mathrm{ci}}$

- h: varies from 1 to 8760 ,

- m: varies from 1 to 12 ,

- $\mathrm{i}_{\mathrm{s}}$ : index of hour 0 of the first day of the month $\mathrm{m}$,

- $\mathrm{i}_{\mathrm{e}}$ : index of hour 23:50 of the last day of the month $\mathrm{m}$.

If the variability of the production is high, such as for wind production, a low-pass filter can be applied to see the tendency for the purpose of interconnection studies. It consists of a simple moving average ${ }^{18}$ in a period $\mathrm{P}$ defined by Equation (2):

$$
M_{k}=\frac{1}{n_{P}} \sum_{i=k}^{k+(n-1)} X_{i}
$$

with:

$\mathrm{M}_{\mathrm{k}}$ : moving average for the step time $\mathrm{k}$,

$\mathrm{n}_{\mathrm{P}}$ : number of step times corresponding to the period $\mathrm{P}$,

$\mathrm{X}_{\mathrm{i}}$, which can be $\mathrm{P}_{\mathrm{i}}, \mathrm{P}_{\mathrm{ci}}, \mathrm{F}_{\mathrm{imH}}$, or $\mathrm{F}_{\mathrm{imM}}$.

\section{II.2.1.2. Season Dependency}

It must be checked that the seasons defined are independent of each other. For that purpose, the following metrics are used.

- The no-production rate over a season $\left(\mathrm{P}_{\mathrm{i} 0}\right)$ : number of hours during the season where the production of DG $\mathrm{i}$ is equal to 0 .

- The maximal production rate over a season $\frac{P_{S s}}{P_{A i}}$, where $\mathrm{P}_{\mathrm{Ss}}$ is the maximal production reached during the season $\mathrm{s}$ and $\mathrm{P}_{\mathrm{Ai}}$ is the maximal production reached during the year for production i.

- For both indictors, 10 and $90 \%$ quantiles are also represented to show the dispersion between the generations of the same type.

II.2.1.3. Daily Dependency

The aggregated production every hour during a given year $\left(\mathrm{P}_{\text {chi }}\right)$ (see Equation (3)) makes it possible to check that there is no dependency at the daily scale. 
with:

$$
P_{c h i}(t)=\frac{\frac{\sum_{d=1}^{364} P_{i}(t+24 d)}{365}}{P_{\text {moy }}(i)} \times 100
$$

- $P_{c h i}$ : aggregated hourly power for production i (\%),

- $\mathrm{t}$ : index of hour, $1 \leq \mathrm{t} \leq 24$,

- d: index of day,

- $P_{\text {moy }}(\mathrm{i})$ : mean annual power of production $\mathrm{i}(\mathrm{kW})$.

\section{II.2.2. PV Case}

The presence of daily cycles for PV makes it impossible to define the seasons in the same way as for CHP, hydraulic, and wind generation. The PV production is directly correlated with the position of the sun and the horizontal solar projection is a good indicator of the dispersion of the PV production values ${ }^{19}$. Then, the year has been split regarding the value of the horizontal solar projection, $\vec{R} \cdot \vec{u}$ (where vectors $\vec{R}$ and $\vec{u}$ are defined in Fig. 2), which varies from -1 to 1 . Four seasons have been arbitrarily created: $-1 \leq \vec{R} \cdot \vec{u} \leq 0$ (night), $0 \leq \vec{R} \cdot \vec{u} \leq 0.5$ (lowangled sun), $0.5 \leq \vec{R} \cdot \vec{u} \leq 0.7$ (day), and $0.7 \leq \vec{R} \cdot \vec{u} \leq 1$ (sun near the zenith). It should be noted that the "seasons" that are created by this method are not continuous.

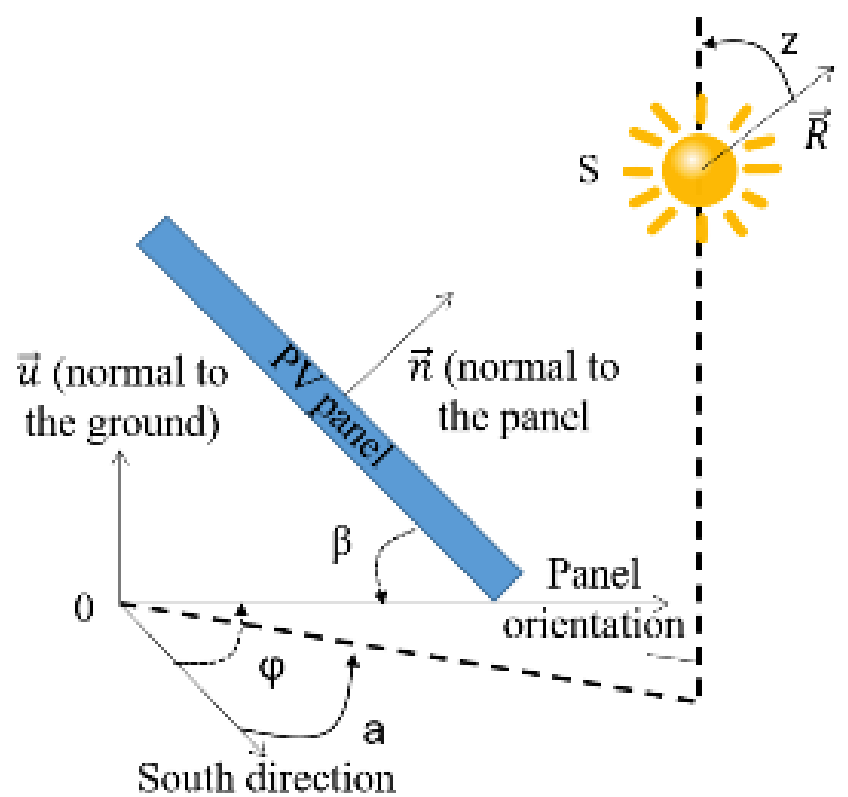

Fig.2 Solar vector received by an inclined PV panel

\section{II.3. Step 3: Probabilistic Law of Production}

Once the seasons have been defined for each production type, the MCDF is defined. As a high number of production measures are available over two years for the four kinds of productions, this metric is representative of the real CDF. The mean MCDF of a given type of production $\mathrm{i}$ is defined by (4):

$$
\forall r \in[0,1], E_{F}(r)=\sum_{i=1}^{n} \frac{F_{i}(r)}{n_{s t}}
$$


with:

- $r$ : power produced (as a percentage of $\mathrm{P}_{\max }$ ),

- $F_{i}: \mathrm{CDF}$ of production $\mathrm{N}^{\circ} \mathrm{i}$,

- $\mathrm{n}_{\mathrm{st}}$ : number of productions of the same type.

\section{II.4. Step 4: Dependency Models}

In this step, the dependency between two producers of the same type, between two producers of different types, and between producers and loads is defined. First a statistical criterion makes it possible to define the type of dependency so that the appropriate model can be chosen. This model will define the mathematical rules that will be applied for basic operations such as the sum of two productions.

\section{II.4.1. Spearman's Rho for Identifying Dependency Relations}

The correlation factor is often used in statistical studies to find a linear dependency between two variables ${ }^{20}$ but its main limitation is that it focuses on linear dependency and does not highlight other kind of dependencies such as quadratic ones. Spearman's rho ${ }^{20}$ is a good indicator because it allows the monotonic dependency of the correlations between variables to be shown. Let $\left(r_{j}\right)_{1 \leq i \leq n}$ and $\left(s_{j}\right)_{1 \leq i \leq n}$ be the rank of two random variables $\mathrm{X}$ and $\mathrm{Y}$. Spearman's rho is given by Equation (5). A coefficient close to 1 indicates a strong correlation between $\mathrm{X}$ and $\mathrm{Y}$ whereas a coefficient close to 0 indicates an absence of correlation between $\mathrm{X}$ and $\mathrm{Y}$.

$$
\rho_{n}=1-\frac{6 \sum_{j=1}^{n}\left(r_{j}-s_{j}\right)^{2}}{n \times\left(n^{2}-1\right)}
$$

\section{II.4.2. The Joint Law}

The way in which two power curves are synchronized is given by the concept of joint law. Let $\mathrm{X}$ and $\mathrm{Y}$ be two random variables. The joint law is the law of the couple $(\mathrm{X}, \mathrm{Y})$.

\section{II.4.2.1. Independent Model of the Joint Law}

$\mathrm{X}$ and $\mathrm{Y}$ are independent if and only if $P(X \mid Y)=P(X)$, where $P(X \mid Y)$ is the probability of $\mathrm{X}$ knowing $\mathrm{Y}$. Let $\mathrm{Z}$ be the random variable so that $\mathrm{Z}=\mathrm{X}+\mathrm{Y}$. If $\mathrm{X}$ and $\mathrm{Y}$ are independent, the $\mathrm{PDF}$ of $\mathrm{Z}, f_{Z}$, is defined by Equation (6) where "*" is the convolution product.

$$
f_{Z}(s)=f_{X} * f_{Y}=\int_{-\infty}^{+\infty} f_{X}(x) f_{Y}(s-x) d x
$$

If Spearman's rho is close to 0, the independent model will be chosen.

\section{II.4.2.2. Model without Diversification of the Joint Law}

If $\left|\rho_{n}(X, Y)\right|=1$ then a linear relation exists between $X$ and $Y$. The CDF of the model without diversification $\mathrm{Z}$ of $\mathrm{X}+\mathrm{Y}$ is defined by Equation (7).

$$
F_{Z}=F_{X}+F_{Y}
$$

If Spearman's rho is close to 1 , the model without diversification will be chosen.

\section{II.4.2.3. Copula}

When Spearman's rho is close to neither 0 nor 1 , the two previous models may not be adapted. In this case, models based on copulas can be investigated. A copula is a mathematical object that allows the dependency of two random variables to be represented without taking account of their marginal laws. A copula $\mathrm{C}$ is a distribution function of the joint $\operatorname{law}\left(F_{X}(X), F_{Y}(Y)\right)^{21}$. For a given pair of producers $\mathrm{P}_{1}$ and $\mathrm{P}_{2}$, the objective is to define a copula $\mathrm{C}_{\mathrm{r}}$ of an arbitrary family that only depends on one parameter $r$ to simplify the problem. The Gaussian copula has 
been chosen, first because it is the only one that can be generalized to higher dimensions and secondly because it is defined by only one parameter. Equation (8) gives the formula of the Gaussian copula in the 2D dimension.

$$
\forall(u, v) \in[0 ; 1]^{2} C_{\rho}(u, v)=\int_{-\infty}^{\varphi^{-1}(u)} \int_{-\infty}^{\varphi^{-1}(v)} \frac{1}{2 \pi \sqrt{1-\rho^{2}}} e^{-\frac{s^{2}-2 \rho s t+t^{2}}{2\left(1-\rho^{2}\right)}} d s d t
$$

with:

- $\rho:$ the linear correlation coefficient between two components

- $\varphi$ : the CDF of the centered reduced normal law

${ }^{22}$ shows that $\rho$ can be estimated by $2 \sin \left(\frac{\pi \rho_{n}}{6}\right)$ when $n$ tends to infinity, where $\rho_{n}$ is the Spearman's rho of two samples $\left(X_{j}\right)_{1 \leq j \leq n}$ and $\left(Y_{j}\right)_{1 \leq j \leq n}$.

\section{II.4.3. Evaluation Indicators}

Two indicators are chosen to evaluate the quality of the joint law models chosen, $\mathrm{K}$ and $\mathrm{N}$, and are given by Equations (9) and (10).

$$
\begin{gathered}
K=\|F-G\|_{\infty}=\max _{[0 ; 1]}|F-G| \\
N=\|F-G\|_{1}=\int_{0}^{1}|F(u)-G(u)| d u
\end{gathered}
$$

Where:

- G: real CDF,

- F: estimated CDF.

$\mathrm{N}$ is the absolute average error in the interval $[0 ; 1]$ and represents how distant $\mathrm{F}$ and $\mathrm{G}$ are from one another, overall. $\mathrm{K}$ is the maximal error in the interval $[0 ; 1]$ and thus represents the statistic dispersion of the data used for the validation. From the Kolmogorov-Smirnov (KS) test ${ }^{16}$, it can be determined whether " $F \neq G$ " with a given level of confidence. If this criterion is not met, it is possible that $\mathrm{G}$ can be modelled by $\mathrm{F}$. Equation (11) gives the test for $\mathrm{G}=F_{X}$ and $\mathrm{F}=F_{Y}$ and Equation (12) gives the test for $\mathrm{F}$ being a given $\mathrm{CDF}$.

$$
\begin{gathered}
\lim _{n \rightarrow+\infty} P\left[\mathrm{~K}>\frac{c}{\sqrt{n}}\right]=\alpha(c) \\
\lim _{n \rightarrow+\infty} P\left[\mathrm{~K}>c \sqrt{\frac{n+m}{n m}}\right]=\alpha(c)
\end{gathered}
$$

$\alpha(c)$ and c are given by Equations (13) and (14).

$$
\begin{gathered}
\alpha(c)=2 \sum_{r=1}^{+\infty}(-1)^{r-1} e^{-2 c^{2} r^{2}} \\
c=\sqrt{-\frac{1}{2} \ln \left(\frac{\alpha}{2}\right)}
\end{gathered}
$$

$\alpha(c)$ is independent of the considered law F. For example, for Equation (11), $F_{X}$ can be approximated by $F_{Y}$ with a probability of $\alpha(c)$ if the maximal gap between $F_{X}$ and $F_{Y}$ is lower than $c \sqrt{\frac{n+m}{n m}} \cdot \operatorname{In}^{9}$, it is proven that $\alpha(1.36)=5 \%$, which means that the probability that the maximal gap between $F_{X}$ and $F_{Y}$ is higher than $1.36 \sqrt{\frac{2}{n}}$ is $5 \%$ if $\mathrm{X}$ and $\mathrm{Y}$ have $\mathrm{n}$ independent trials. If the maximal gap between $F_{X}$ and $F_{Y}$ is lower than $1.36 \sqrt{\frac{2}{n}}$ then we can conclude that 
$F_{X}$ can be approximated by $F_{Y}$. If $\mathrm{n}$ is equal to 200 , then the limit value of $\mathrm{K}$ is $1.36 \sqrt{\frac{2}{200}}=$ $13.6 \%$.

\section{French Case Studied}

\section{III.1. Description}

The real dataset consists of 4254 producers (514 CHPs, 806 wind, 1202 hydraulic, 676 PV) and gives information on the type of production and its 10-minute mean produced power for the years 2012 and 2013 in kilowatts. In this paper, all the numerical values will be given as percentages of the maximal power.

\section{III.2. Seasons}

\section{III.2.1. Co-Generation}

CHP is totally controllable and therefore is expected to produce it maximal power at all times except in the case of outages, maintenance periods, or no-production periods imposed by the regulations of the country. Then the direct observation of $\mathrm{P}_{\mathrm{C}}$ and the method of remuneration allows the seasons of productions to be defined easily. Fig. 3 shows the percentage of CHPs that are active during 2012 as a function of the months. Two seasons can be identified: the "CHP winter", in which almost all producers are active, and the "CHP summer" (from April to October), in which almost all production is inactive except for a few local peaks due to maintenance tests. This is coherent with the French regulation ${ }^{23}$, where the regulation of the tariffs for CHPs incentivizes them to produce during the winter.

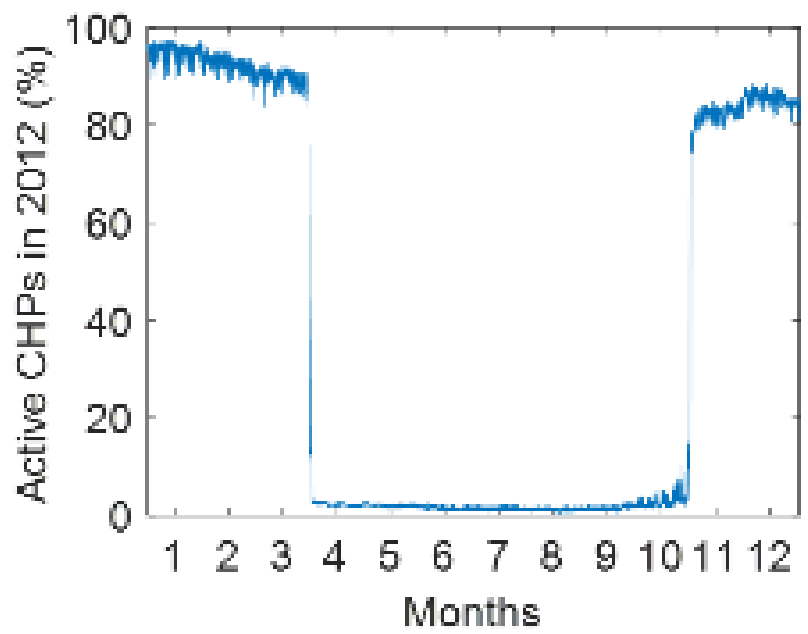

\section{III.2.2. Wind}

Fig.3 Co-generation producers active in 2012 at the national level

Wind power has a high degree of variability, as shown in Fig. 4, where the left figure gives the aggregated wind production $\left(\mathrm{P}_{\mathrm{cW}}\right)$ and the mean associated production factor $\left(\mathrm{F}_{\mathrm{WmH}}\right)$ for 2012 and 2013. The low-pass filter presented in Section II-B-1-A has been applied with a period of two months and the results are depicted in Fig. 5. Two seasons appear with a low production from June to October and a high production from November to May. Then a network having both CHP and wind can be split into three seasons: winter (from November to March), spring (from April to May), and summer (from June to October). The aggregated production for every hour during both 2012 and 2013 has been computed. Even if a low production appears in the morning and the production increases at the end of the day and during the night, these variations remain under $+/-10 \%$ of the annual mean value and therefore it can be assumed that there is 
no significant daily dependency. Finally, the season dependency is illustrated in Fig. 6 with the two indicators $\frac{\mathrm{P}_{\mathrm{SW}}}{\mathrm{P}_{\mathrm{AW}}}$ and the no-production rate computed for the three seasons. The maximal production is at $100 \%$ of the maximal annual production for at least $10 \%$ of the producers and the mean is close to $100 \%$. The winter and spring seasons have the same behaviour, as expected (only two seasons for wind). During the summer, there are slightly more periods with zero production.
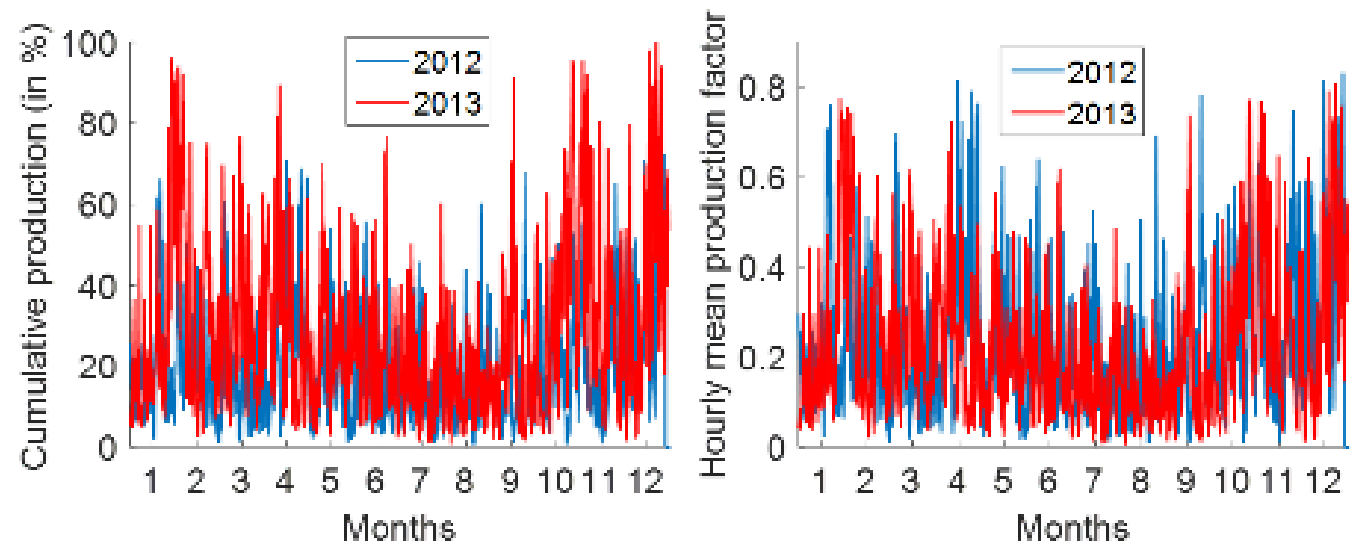

Fig. $4 \mathrm{P}_{\mathrm{cW}}$ (left figure) and associated $\mathrm{F}_{\mathrm{WmH}}$ (right figure) for 2012 and 2013

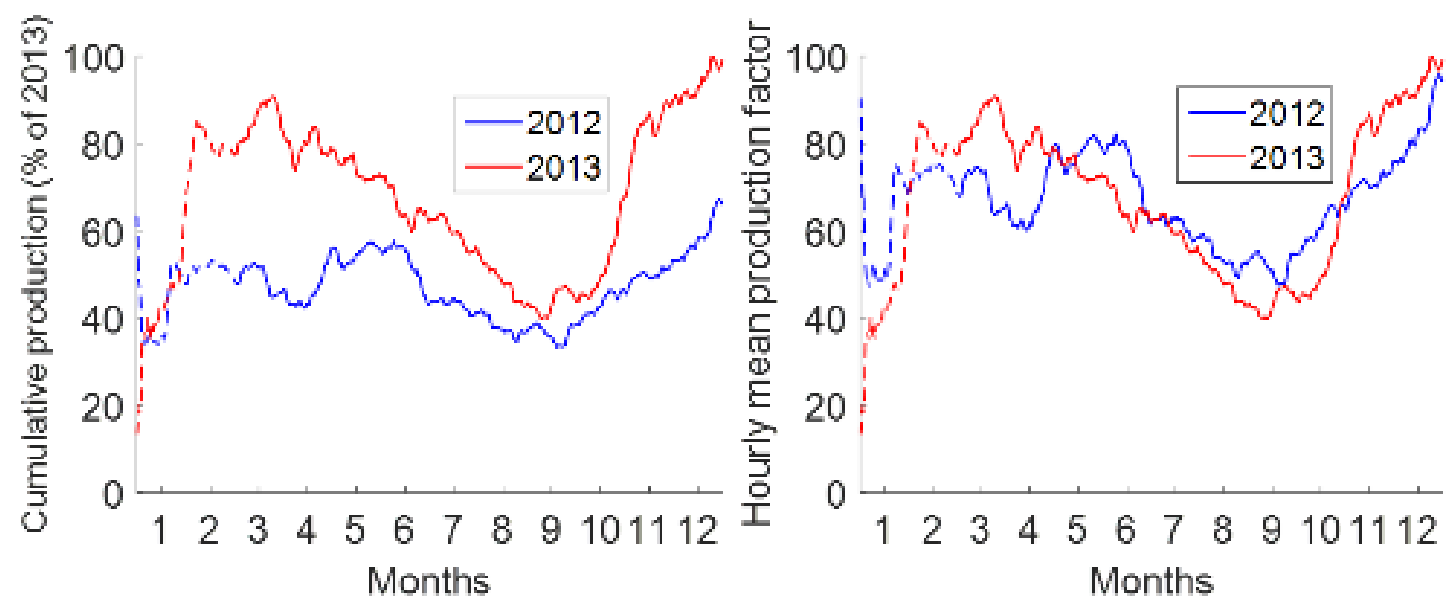

Fig. $5 \mathrm{P}_{\mathrm{cW}}$ (left figure) and associated $\mathrm{F}_{\mathrm{WmH}}$ (right figure) for 2012 and 2013 after applying a low-pass filter 

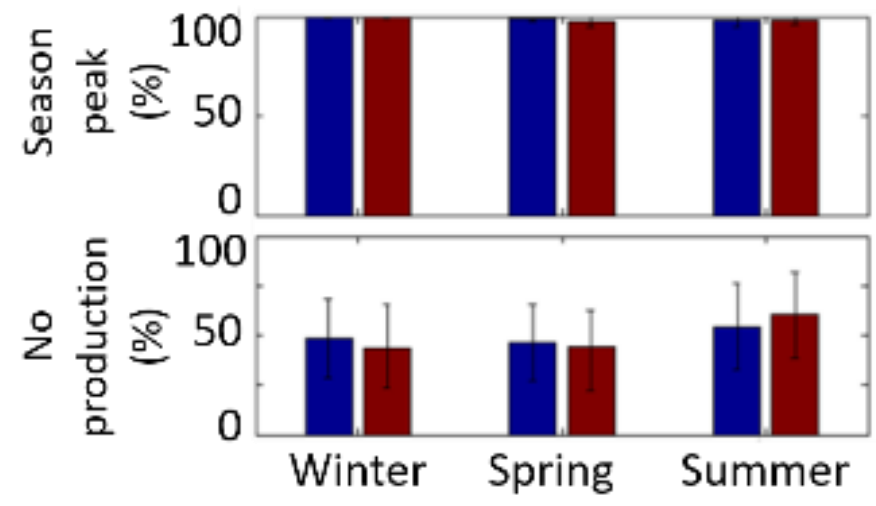

Fig.6 $\frac{\mathrm{P}_{\mathrm{SW}}}{\mathrm{P}_{\mathrm{AW}}}$ and no-production rate for 2012 (blue) and 2013 (red) for wind

\section{III.2.3. Hydraulic}

The degree of variability of hydraulic power is lower than that of wind and is linked with the flow of streams, which depends on the weather conditions. Fig. 7 shows the aggregated hydraulic production $\left(\mathrm{P}_{\mathrm{cH}}\right)$ for 2012 and 2013 and the mean associated production factor $\left(\mathrm{F}_{\mathrm{HmH}}\right)$. Fig. 8 provides a boxplot of the production factor per month FHmM to study the dispersion of the different producers. Two seasons can be identified: the "hydraulic summer", in which the production is low, from July to October, and the "hydraulic winter", when the production is high, from November to June. A high dispersion of the production factor can be seen, which may be due to a high technological and/or geographical dispersion. The same conclusion can be drawn regarding the daily and seasonal dependencies as for the wind production. The aggregated production for every hour remains under $+/-5 \%$. As for wind, the winter and spring seasons have the same behaviour regarding the maximal production and no-production rates. Compared to wind, a larger dispersion can be seen; thus the activity of hydraulic power in winter and spring remains undetermined.
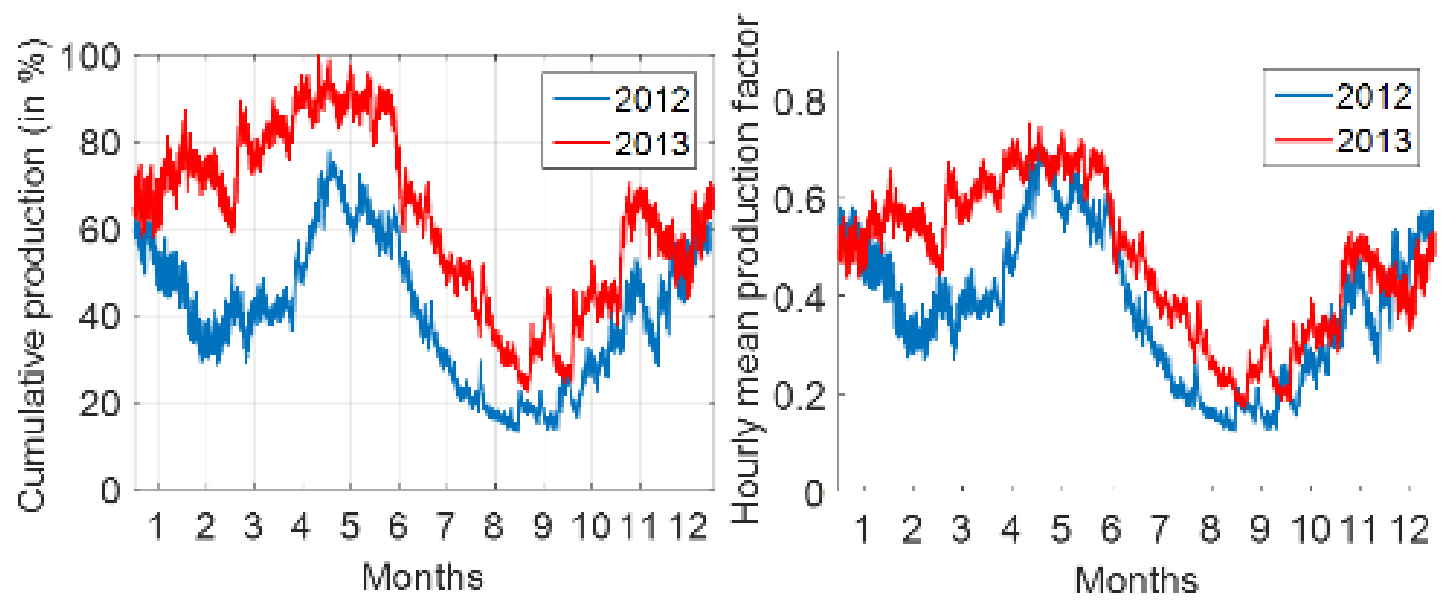

Fig.7 $\mathrm{P}_{\mathrm{cH}}$ (left figure) and associate $\mathrm{F}_{\mathrm{HmH}}$ (right figure) for 2012 and 2013 


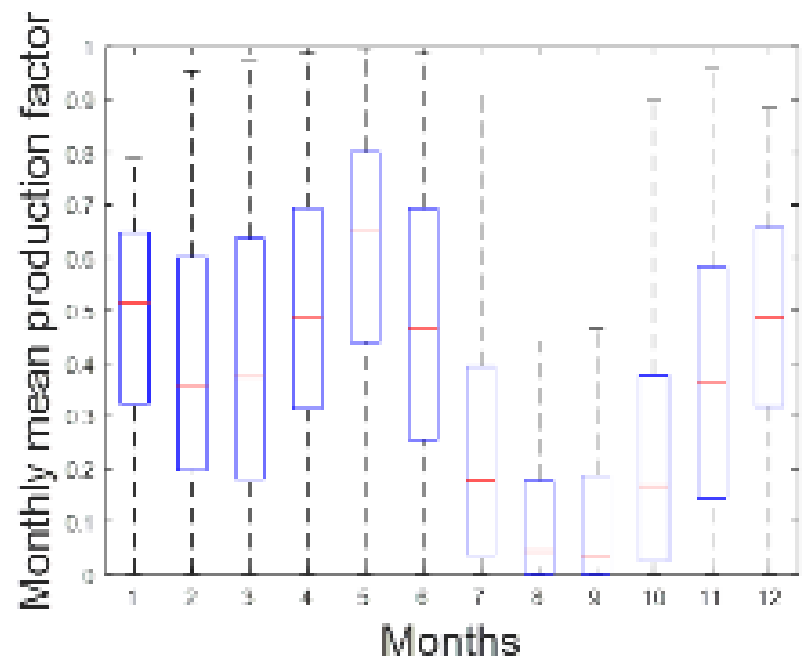

III.2.4. PV

Fig.8 $\mathrm{F}_{\mathrm{HmH}}$ dispersion of wind producers for 2012

In Fig. 9, the mean production factor and the maximal production reached during the four seasons defined in Section II-B-4 have been plotted. As expected, $\vec{R} \cdot \vec{u}$ is strongly correlated with the PV production. The dispersion around the mean value for each season decreases when $\vec{R} \cdot \vec{u}$ is higher than 0.5 . During night and dusk, $-1 \leq \vec{R} \cdot \vec{u} \leq 1$, the mean load factor is close to 0 and the no-production period is close to $100 \%$. Then the mean load factor increases, with $\vec{R} \cdot \vec{u}$ reaching a mean value close to 0.6 , and the no-production rate decreases almost to $0 \%$.
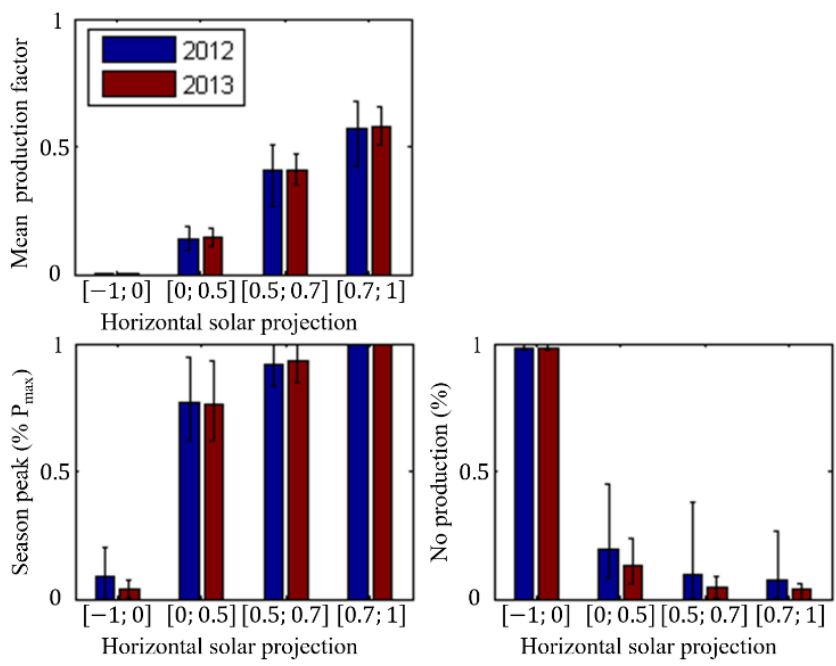

Fig.9 Mean production factor, maximal production, and no-production rate reached for 2012 (blue) and 2013 (red)

\section{III.2.5. Conclusion}

Table I summarizes the seasons found for a network having the four types of productions. Twelve seasons can be defined: three defined by CHP, hydraulic, and wind generation, each of which is split into four solar seasons.

TABLE I

DIVISION OF SEASONS FOR A NETWORK HAVING FOUR TYPES OF PRODUCTIONS 


\begin{tabular}{|c|c|c|c|}
\hline & $\begin{array}{c}\text { Winter } \\
31 / 10 \text { to } 31 / 03\end{array}$ & $\begin{array}{c}\text { Spring } \\
01 / 04 \text { to } 30 / 06\end{array}$ & $\begin{array}{c}\text { Summer } \\
01 / 07 \text { to } 31 / 10\end{array}$ \\
\hline $\mathrm{H}$ & Undetermined & Undetermined & Low \\
\hline $\mathrm{W}$ & High & High & Low \\
\hline $\mathrm{C}$ & Active & \multicolumn{2}{|c|}{ Inactive } \\
\hline $\mathrm{P}$ & & $\begin{array}{l}\text { ns are split into } \\
-1 \leq \vec{R} \cdot \vec{u} \leq \\
0 \leq \vec{R} \cdot \vec{u} \leq 0 \\
0.5 \leq \vec{R} \cdot \vec{u} \leq 0 \\
0.7 \leq \vec{R} \cdot \vec{u} \leq\end{array}$ & ns: \\
\hline
\end{tabular}

III.3. Dependency Models

III.3.1. Productions of the Same Type

For each pair of producers connected to the same HV/MV substation, the Spearman's rho is computed for the entire year and for the seasons defined in the previous part. Table II gives the mean and standard deviation of Spearman's rho. It can be seen that PV and wind present an autocorrelation close to 1 with a low dispersion, showing that a model without diversification is adapted. This is coherent with the fact that at HV/MV substation scale, the geographical hazards (temperature, sun, wind) are quite homogeneous. This model is compared with the real CDF obtained after summing the production time series. Table III gives the mean values and the $95 \%$ quantile of $\mathrm{K}$ and $\mathrm{N}$ expressed as a percentage.

TABLE II

MEAN AND STANDARD DEVIATION OF THE SPEARMAN's RHO (PRODUCTIONS OF THE SAME TYPES)

\begin{tabular}{|l|l|l|l|l|l|l|l|l|}
\hline & \multicolumn{2}{|c|}{ Annual } & \multicolumn{2}{c|}{ Winter } & \multicolumn{2}{c|}{ Spring } & \multicolumn{2}{c|}{ Summer } \\
\hline & \multicolumn{1}{|c|}{$\mu$} & $\sigma$ & $\mu$ & $\sigma$ & $\mu$ & $\sigma$ & $\mu$ & $\sigma$ \\
\hline $\mathrm{H}$ & 0.42 & 0.34 & 0.34 & 0.37 & 0.31 & 0.34 & 0.37 & 0.32 \\
\hline $\mathrm{W}$ & 0.81 & 0.22 & 0.81 & 0.22 & 0.86 & 0.17 & 0.84 & 0.17 \\
\hline $\mathrm{P}$ & 0.89 & 0.15 & 0.85 & 0.19 & 0.91 & 0.14 & 0.93 & 0.09 \\
\hline $\mathrm{C}$ & 0.72 & 0.27 & 0.21 & 0.28 & 0.59 & 0.35 & 0.05 & 0.16 \\
\hline
\end{tabular}

It can be seen that the mean value of $\mathrm{K}$ and its $95 \%$ quantile is lower than $13.6 \%$, showing 
that the joint law of PV and wind can be represented by the model without diversification. The Spearman's rho of hydraulic production and CHP has a high dispersion, showing that a deeper investigation is required.

TABLE III

MEAN AND 95\% QUANTILE OF K AND N

\begin{tabular}{|c|c|c|}
\hline & WI & PV \\
\hline K mean & 3.28 & 1.74 \\
\hline K 95\% quantile & 8.40 & 5.37 \\
\hline N mean & 0.76 & 0.45 \\
\hline N 95\% quantile & 2.21 & 1.67 \\
\hline
\end{tabular}

\section{III.3.1.1. C CHP}

The Spearman's rho for CHP can be negative, positive, or close to zero. The negative values correspond to two specific cases of low production in normally high periods of production that are not representative of the standard case and could be due to abnormal data. For producers having a Spearman's rho close to 0 or positive, the independent model fits well during the winter season, especially for high values.

\section{III.3.1.2. Hydraulic}

The hydraulic production dataset has the particularity of having quite important nonoperating ranges, probably due to maintenance. But these ranges are not predictable and vary from one producer to another. Thus neither the independent model nor the model without diversification can be used. Therefore, a hybrid model based on the Gaussian copula has been investigated because it makes it possible to focus only on the dependency between two productions. Two hydraulic productions have been arbitrarily chosen. Only the time during which the two productions are active is considered. The corresponding Spearman's rho is 0.6. Fig. 10 shows the empirical copula (left figure) and the Gaussian copula (right figure) built using the methodology explained in Section II-D-2-c and parameterized with 0.6. The Gaussian copula fits the empirical law very well, including for high production values.

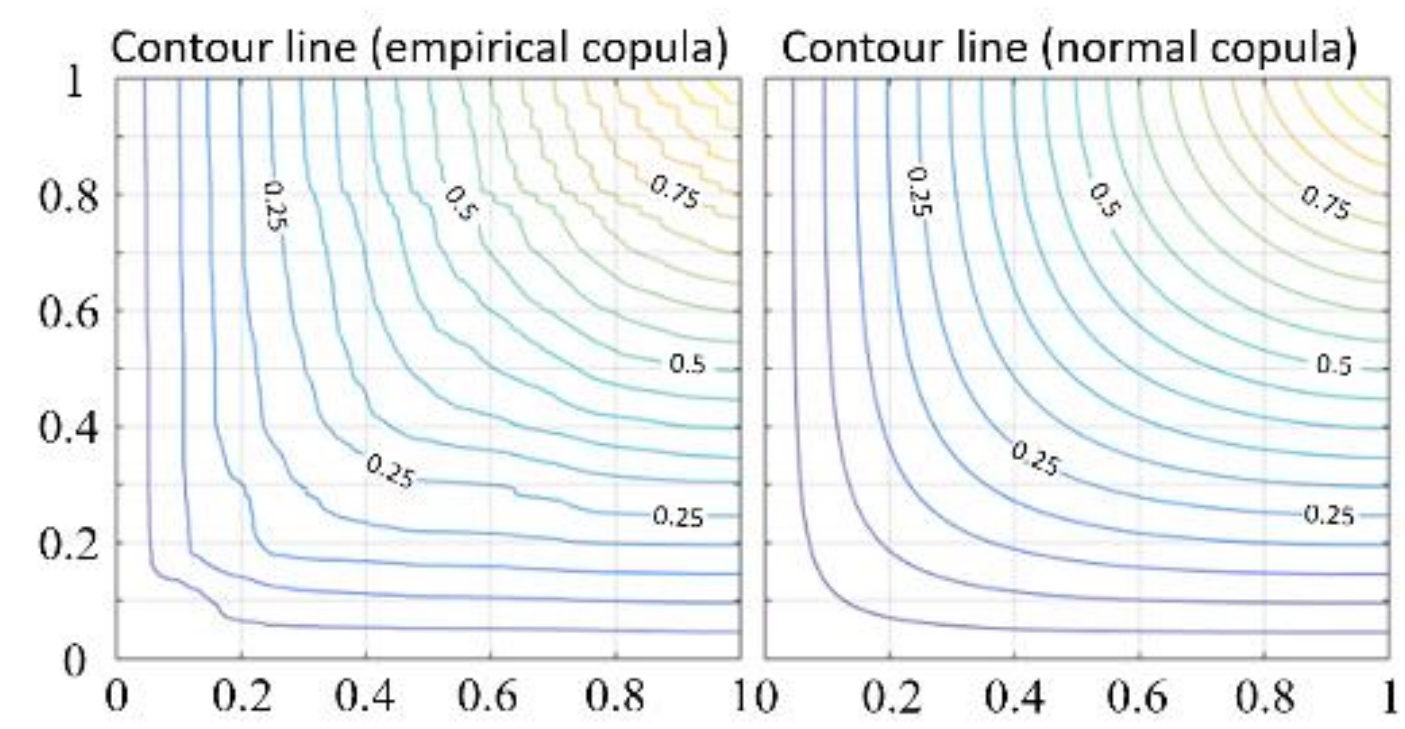

Fig. 10 Comparison between the empirical and Gaussian contour lines for the hydraulic production

\section{III.3.2. Productions of Different Types}

Table IV shows the annual Spearman's rho obtained for productions of different types. 
TABLE IV

MEAN AND STANDARD DEVIATION OF SPEARMAN'S RHO (PRODUCTIONS OF DIFFERENT TYPES)

\begin{tabular}{|c|c|c|c|c|c|c|}
\hline & \multicolumn{2}{|c|}{ W } & \multicolumn{2}{|c|}{$\mathrm{P}$} & \multicolumn{2}{|c|}{ C } \\
\hline & $\mu$ & $\sigma$ & $\mu$ & $\sigma$ & $\mu$ & $\sigma$ \\
\hline $\mathrm{H}$ & 0.08 & 0.11 & -0.02 & 0.11 & 0.14 & 0.31 \\
\hline W & & & -0.01 & 0.09 & 0.09 & 0.09 \\
\hline $\mathrm{P}$ & & & & & -0.17 & 0.09 \\
\hline
\end{tabular}

The Spearman's rho is close to 0 , which is a necessary but not sufficient condition for independence. In order to validate the independent model, the KS test is carried out on the independent model of the sum and the real data obtained by actually summing two time-series production profiles taken over 400 randomly chosen step times. Indeed, the values of a given time-series profile are not independent and so the KS test cannot be directly applied. By observing the dispersion between 2012 and 2013, it can be seen that considering a few hundred samples allows samples that are quite independent (autocorrelation coefficient close to 0 ) to be obtained. The limit value of $\mathrm{K}$ is thus $\frac{1.36}{\sqrt{400}}=6.8 \%$, as explained by Equation (12). If $\mathrm{K}$ is lower than $6.8 \%$, then the independent model represents the dependency between productions of different types. Table $\mathrm{V}$ provides the mean value and the $95 \%$ quantile of $\mathrm{K}$. It can be seen that the independent model can be used to model the dependency of two productions of the same type except for CHP with hydraulic and CHP with PV. In the case of CHP, only the winter season (active season) is considered and Spearman's rho is computed.

\section{TABLE V}

THE MEAN VALUE AND 95\% QUANTILE OF K FOR PRODUCTIONS OF DIFFERENT TYPES

\begin{tabular}{|l|l|l|l|l|l|l|}
\hline & \multicolumn{2}{|c|}{ WI } & \multicolumn{2}{c|}{ PV } & \multicolumn{2}{c|}{ CO } \\
\hline & $\mathrm{K}_{\text {mean }}$ & $\mathrm{K}_{95 \%}$ & $\mathrm{~K}_{\text {mean }}$ & $\mathrm{K}_{95 \%}$ & $\mathrm{~K}_{\text {mean }}$ & $\mathrm{K}_{95 \%}$ \\
\hline HY & 3.95 & 7.39 & 4.11 & 7.85 & 9.43 & 16.23 \\
\hline WI & & & 3.59 & 7.06 & 4.26 & 7.75 \\
\hline PV & \multicolumn{3}{|c}{} & \multicolumn{5}{c}{5.94} & 10.15 \\
\hline
\end{tabular}

\section{III.3.3. Productions and Loads}

In this part, the real values of power measured at the HV/MV substation are plotted in red. The models of production minus consumption are plotted by black dots (model without diversification) and blue dots (independent model). It is assumed that the DSO has a good knowledge of the load profiles thanks to smart metering.

\section{III.3.3.1. $\quad$ CHP}

The HV/MV substation 2A-P6 has two CHPs. For this substation, the time series of the total consumption and total productions are available. Fig. 11 compares the real CDF with the model without diversification and the independent model during the winter season (left figure) and the summer season (right figure). The independent model is able to model the difference between load and co-generation very accurately. The need to consider two seasons for CHP can be illustrated by Fig. 12, which is the same as Fig. 11 except that it does not split the data into two seasons. In this case, it can be seen that the models do not fit the real CDF at all. The mean value of $\mathrm{K}$ is $1.16 \%$ in winter and $0.67 \%$ in spring/summer for the independent model whereas it is $10.07 \%$ for the annual case. 


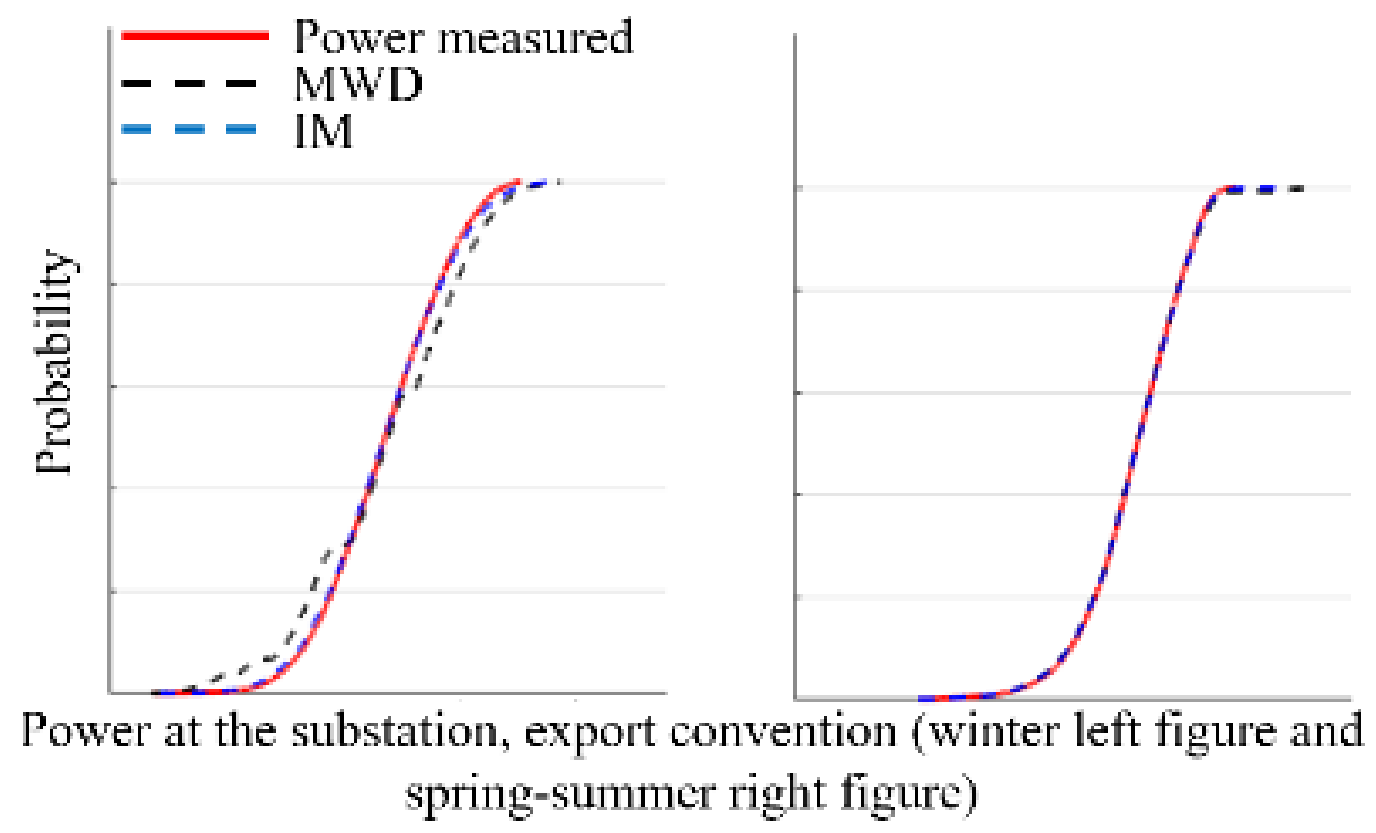

Fig.11 Comparison between empirical law and models (two seasons)

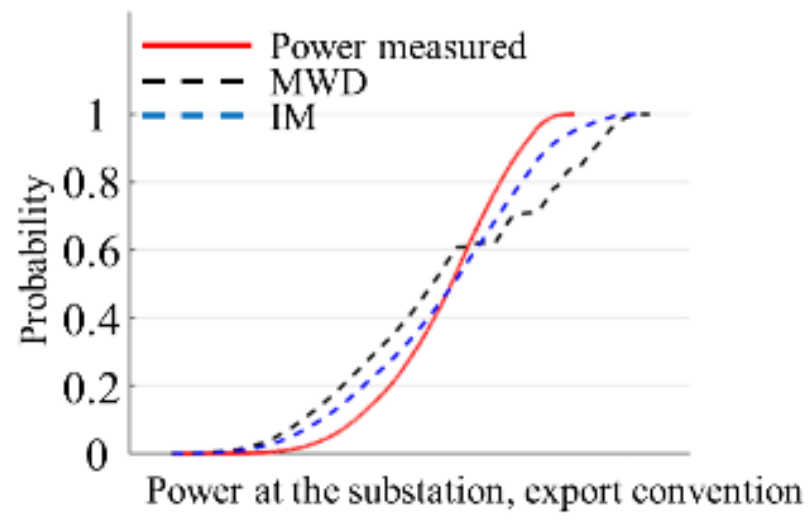

Fig.12 Comparison between empirical law and models (one season)

\section{III.3.3.2. Wind, Hydraulic, and PV}

The same investigations as for CHP have been done for the wind, hydraulic, and PV cases. Again, the independent model fits the empirical law of production minus consumption very well. The values of $\mathrm{K}_{\text {mean }}$ vary from 1.35 to $2.30 \%$ for wind generation, from 1.7 to $4.56 \%$ for hydraulic generation, and from $0.8 \%$ to $2.69 \%$ for PV generation regarding the seasons.

III.3.4. Conclusion

Table VI summarizes the adequate model as a function of the type of production studied. The following additional acronyms are used: LO (load), IM (independent model), MWD (model without diversification), and GCM (Gaussian copula model). The model for the sum of productions of different types will be the independent model except for co-generation with hydraulic and PV generation.

\section{TABLE VI}

SUMMARY OF THE DEPENDENCY MODELS BETWEEN PRODUCTIONS AND BETWEEN PRODUCTIONS AND LOAD FOR EVERY SEASON PROVIDED BY TABLE I. 


\begin{tabular}{|l|l|l|l|l|l|}
\hline & WI & PV & HY & CHP (winter) & LO \\
\hline WI & MWD & IM & IM & IM & IM \\
\hline PV & & MWD & IM & & IM \\
\hline HY & & & GCM & & IM \\
\hline CO & & & & IM & IM \\
\hline
\end{tabular}

III.4. Application to a PV interconnection study to a real French distribution network

III.4.1. Definition of the case study

A real distribution feeder whose characteristics are provided in Table VII is depicted in Fig. 13. A wind generator is already connected and a PV producer asks for being connected to the DN. The interconnection study will consist of two steps:

- Step 1: Constraints analysis

Powers will be modelled as random variables defined as explained in Section III-B. Two seasons are considered for wind and four for PV. Then the year is split into eight seasons, where the MCDFs (see Equation (4)) of PV and wind are defined. It is assumed that the CDF of the load is known by the DSO (thanks to smart meters) for these eight seasons. The independent model of load, PV, and wind for each season has been used according to Table VI. A quadratic probabilistic load flow whose principles are explained in Brucoli and al.'s paper $^{24}$ has been used to perform the estimation of the voltages at each node with good accuracy. If current or voltage constraints appear, step 2 is run.

- Step 2: Technical solutions to cope with constraints violation.

- Traditional interconnection rule (solution 1): the DSO will perform a reinforcement whose cost will be borne by the producer. The reinforcement of lines consists in replacing the existing lines by lines having a bigger section. Indeed, increasing the section of a line decreases its resistance and so the voltage drop too.

- Non-wire interconnection rule (solution 2): if the PV producer accepts a reduction in its production during some moments of the year, the reinforcement will be postponed and the producer will not be charged. It is assumed that a simple decentralized curtailment control is used. If the voltage measured at the PV node exceeds the limit then the PV production is reduced until the constraint is solved. 


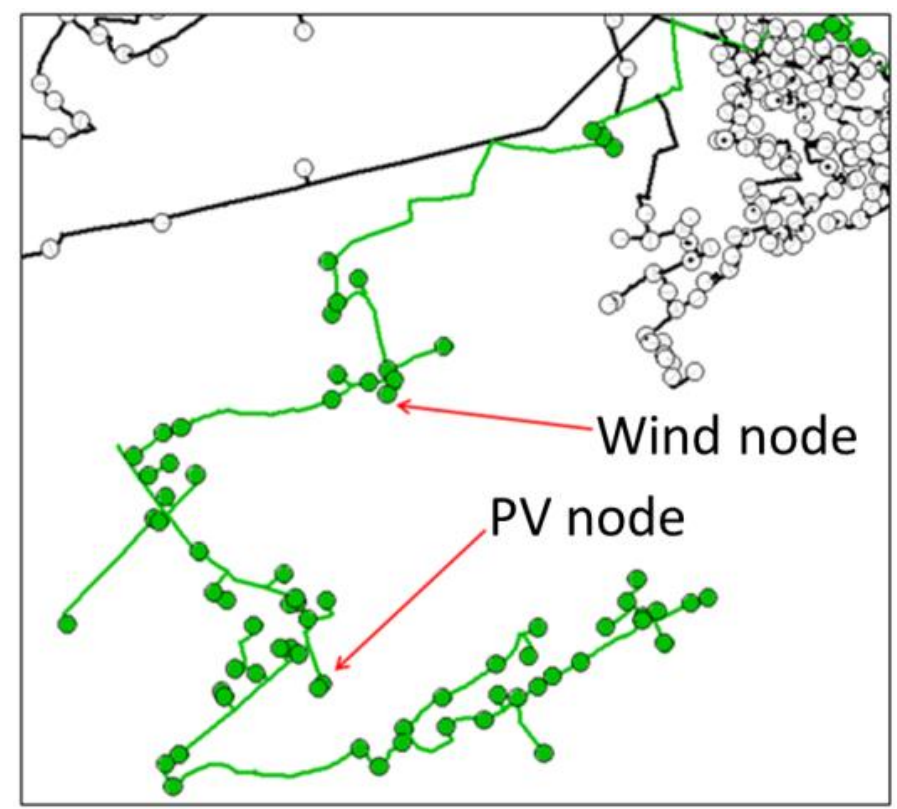

Fig.13 Real French distribution MV feeder

TABLE VII

CHARACTERISTICS OF THE REAL FRENCH DISTRIBUTION FEEDER

\begin{tabular}{|c|c|}
\hline \multicolumn{2}{|c|}{ Network parameters } \\
\hline$P_{\max }$ & $4.8 \mathrm{MW}$ \\
\hline $\operatorname{Tan} \varphi$ & 0.4 \\
\hline Number of $\mathrm{HV} / \mathrm{MV}$ substations & 183 \\
\hline Total length of the feeder & $32 \mathrm{~km}$ \\
\hline Nominal voltage at the HV/MV transformer secondary & $1.02 \mathrm{pu}$ \\
\hline Line reinforcement cost & $100 \mathrm{k} € / \mathrm{km}$ \\
\hline \multicolumn{2}{|l|}{ Wind } \\
\hline Maximal power & $1.5 \mathrm{MW}$ \\
\hline Distance to the HV/MV substation & $15.1 \mathrm{~km}$ \\
\hline \multicolumn{2}{|l|}{ PV } \\
\hline Maximal power & $2 \mathrm{MW}$ \\
\hline Distance to the HV/MV substation & $22.8 \mathrm{~km}$ \\
\hline
\end{tabular}

\section{III.4.2. Results}

\section{III.4.2.1. Constraints analysis (step 1)}

The results of the constraints analysis is depicted in Fig. 14 that shows the MCDF of the voltage at the wind node (in green) and at the PV node (in red) without PV connected (left figure) and with PV connected (right figure). The third figure in Fig.14 is a zoom of the right figure. It can be seen that without PV, the voltage remains within the limits, whereas when PV 
is connected, the voltage at the PV node can exceed $1.04 \mathrm{pu}$. Indeed, the on-load tap changer has a precision of $0.01 \mathrm{pu}$ and thus the maximal admissible voltage at the HV/MV substation is $1.04 \mathrm{pu}$ to ensure that the voltage remains below $1.05 \mathrm{pu}$.

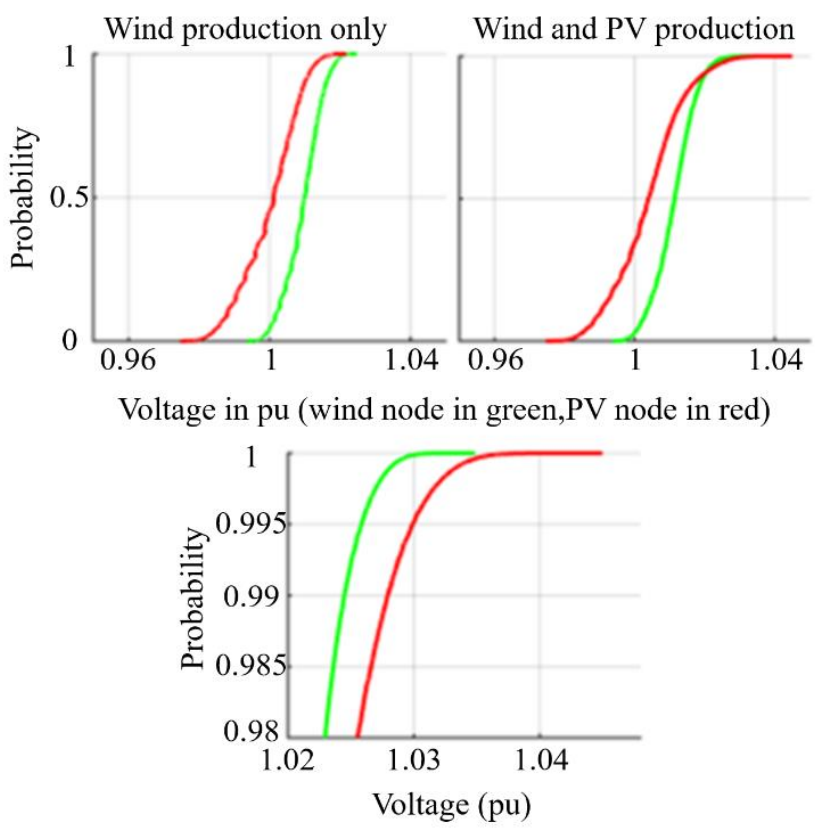

Fig.14 Probabilistic voltages at the PV and wind nodes with and without PV connected

\section{III.4.2.2. Traditional interconnection rule (step 2, solution 1)}

To solve the over-voltage constraint caused by the PV connection, 14 overhead lines with a current section of $54 \mathrm{~mm}^{2}$ have to be upgraded with a section of $240 \mathrm{~mm}^{2}$, which represents a total length of $3.7 \mathrm{~km}$. The producer will have to pay $370 \mathrm{k} €$ to be connected to the distribution network based on the reinforcement cost shown in Table VII. Fig. 15 shows the MCDF of the voltage at the wind and PV nodes after reinforcement. The solid lines represent the results obtained using the probabilistic season-based modelling and the dotted lines represent the ones using real time series data with a load flow every 10 minutes. First it can be seen that the proposed reinforcement does solve the over-voltage problem. Then the modelling methodology of producers/consumers gives almost the same results as the real data.

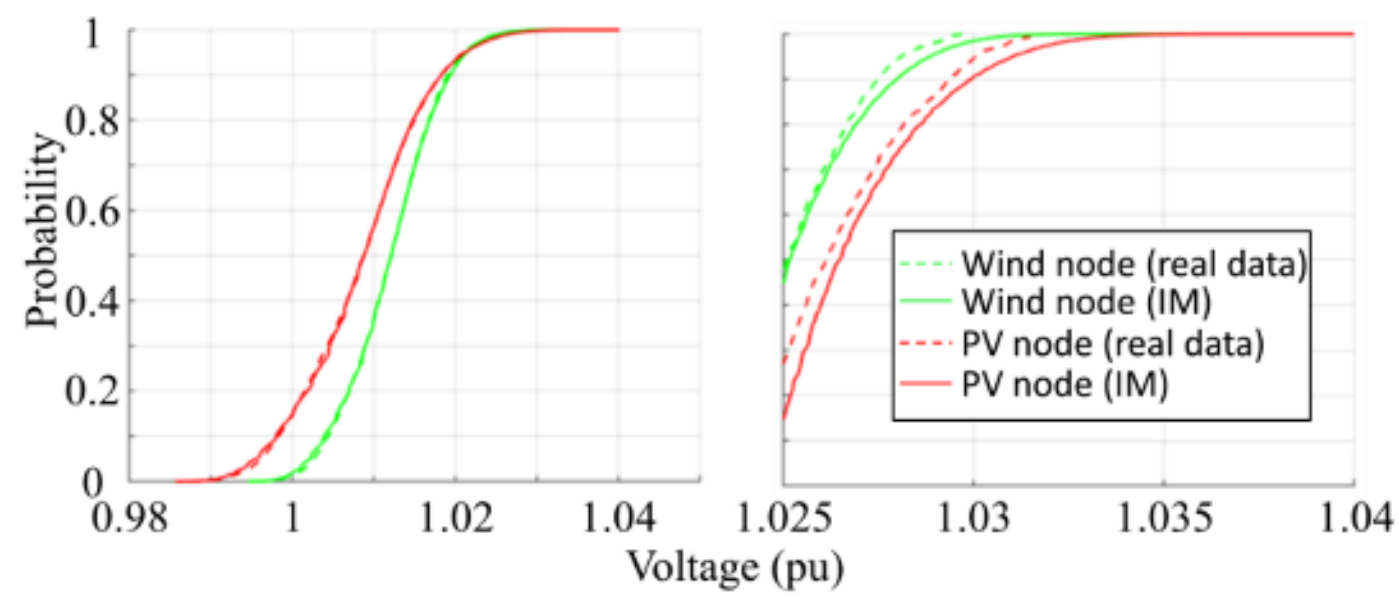

Fig.15 Real and probabilistic voltages at the PV and wind nodes after network 
reinforcement

\section{III.4.2.3. Non-wire interconnection rule (step 2, solution 2)}

In this case, $72 \mathrm{MWh}$ of PV curtailment over the year is required. Then if $\mathrm{C}_{\mathrm{C}}$ is the cost of curtailment (in $€ / \mathrm{kWh}$ ) and if $C_{C}$ is lower than $370 / 72=5.1 \mathrm{k} € / \mathrm{kWh}$, then the curtailment is more interesting than the reinforcement. The cost of the remuneration of PV in France in 2017 for installation between $100 \mathrm{kWp}$ and $12 \mathrm{MWp}$ is $5.36 \mathrm{c} € / \mathrm{kWh}$ for PV guaranteed for 20 years ${ }^{25}$. Thus the cost of curtailment for this PV producer would be at most $3.8 \mathrm{k} € /$ year. Considering that the lifespan of a PV installation does not exceed 30 years, the actualized cost of this loss of energy every year during 30 years would be $45.57 \mathrm{k} €$, considering a discount rate of $8 \%$. The curtailment solution is at least eight times more economic than the reinforcement in this case.

\section{Conclusion}

In this paper, a statistical methodology has been proposed to develop probabilistic models of different types of productions. The use of 4254 ten-minute production time series made it possible to propose seasons for each type of production which could be modelled by a CDF. Then a table of dependencies between productions and between productions and loads was established to make it possible to choose the appropriate mathematical rules in an interconnection study. These models have been validated on the example of the connection of a PV production to a distribution feeder, which creates a voltage constraint. An alternative solution (curtailment) is proposed to the producer in order to avoid reinforcement. Although these results are specific to France, the methodology is replicable for any utility that has data available. To the best of the authors' knowledge, there is no other paper in the literature that proposes these kinds of models for the four types of common distributed generation encountered in the DN and which validates them on such a large amount of real data. This methodology can of course be enriched with other kinds of data as well as with other models (such as other copula models). In addition, since the probabilistic models are based only on the data from the past, the conclusion and analysis have to be refreshed with the improvement of DG technologies and control.

\section{List of Symbols}

\begin{tabular}{|l|l|}
\hline$i$ & $\begin{array}{l}\text { Index of type of generation } \\
\mathrm{i}=\mathrm{C} \text { for } \mathrm{CHP}, \mathrm{i}=\mathrm{H} \text { for hydraulic, } \mathrm{i}=\mathrm{W} \text { for wind, and } \mathrm{i}=\mathrm{P} \text { for } \mathrm{PV}\end{array}$ \\
\hline$n_{i}$ & Number of time series of production of type $\mathrm{i}$ \\
\hline$y_{i}$ & Number of years of production time series of type $\mathrm{i}$ available \\
\hline $\mathrm{P}_{\max }(\mathrm{i})$ & Maximal annual production of type $\mathrm{i}$ \\
\hline $\mathrm{P}_{\mathrm{i}}$ & Output power for production $\mathrm{i}$ time series \\
\hline $\mathrm{P}_{\mathrm{ci}}$ & Aggregated production of type $\mathrm{i}$ \\
\hline $\mathrm{F}_{\mathrm{imH}}$ & Hourly mean production factor \\
\hline $\mathrm{F}_{\mathrm{imM}}$ & Monthly mean production factor \\
\hline $\mathrm{P}^{\prime}{ }_{\mathrm{i}}$ & $\mathrm{P}_{\mathrm{i}}$ or $\mathrm{P}_{\mathrm{ci}}$ \\
\hline $\mathrm{h}$ & Index of hours between 1 and 8760 \\
\hline $\mathrm{m}$ & Index of month \\
\hline $\mathrm{i}_{\mathrm{s}}$ & Index of hour 0 of the first day of the month $\mathrm{m}$ \\
\hline $\mathrm{i}_{\mathrm{e}}$ & Index of hour $23: 50$ of the last day of the month $\mathrm{m}$ \\
\hline $\mathrm{M}_{\mathrm{k}}$ & Moving average for the step time $\mathrm{k}$ \\
\hline $\mathrm{k}$ & Index of time \\
\hline
\end{tabular}




\begin{tabular}{|l|l|}
\hline $\mathrm{n}_{\mathrm{P}}$ & Number of step times corresponding to the period $\mathrm{P}$ \\
\hline $\mathrm{X}_{\mathrm{i}}$ & $\mathrm{P}_{\mathrm{i}}, \mathrm{P}_{\mathrm{ci}}, \mathrm{F}_{\mathrm{imH}}$, or $\mathrm{F}_{\text {imM }}$ \\
\hline $\mathrm{P}_{\mathrm{i} 0}$ & No-production rate over a season \\
\hline $\mathrm{s}$ & Index of season \\
\hline $\mathrm{P}_{\mathrm{Ss}}$ & Maximal production reached during the season $\mathrm{S}$ \\
\hline $\mathrm{P}_{\mathrm{Ai}}$ & Maximal production reached during the year for production $\mathrm{i}$ \\
\hline $\mathrm{P}_{\mathrm{chi}}$ & Aggregated hourly power for production $\mathrm{i}$ \\
\hline $\mathrm{t}$ & Index of hour (between 1 and 24$)$ \\
\hline $\mathrm{d}$ & Index of day \\
\hline $\mathrm{P}_{\mathrm{moy}}(\mathrm{i})$ & Mean annual power of production $\mathrm{i}$ \\
\hline$\vec{R} \cdot \vec{u}$ & Horizontal solar projection \\
\hline $\mathrm{r}$ & Power produced (as a percentage of $\left.\mathrm{P}_{\max }\right)$ \\
\hline$F_{i}$ & Cumulative density function of production $\mathrm{N}{ }^{\circ} \mathrm{i}$ \\
\hline $\mathrm{n}_{\mathrm{st}}$ & Number of productions of the same type \\
\hline $\mathrm{X}, \mathrm{Y}, \mathrm{Z}$ & Random variables \\
\hline $\mathrm{n}$ & Number of components of the random variable $\mathrm{X}$ and $\mathrm{Y}$ \\
\hline$\left(r_{j}\right)_{1 \leq i \leq n}$ & Rank of a random variable $\mathrm{X}$ having $\mathrm{n}$ components \\
\hline$\left(s_{j}\right)_{1 \leq i \leq n}$ & Rank of a random variable $\mathrm{Y}$ having $\mathrm{n}$ components \\
\hline $\mathrm{j}$ & jème component of a random variable \\
\hline$\rho_{n}$ & Spearman's rho of variables $\mathrm{X}$ and $\mathrm{Y}$ \\
\hline$P(X \mid Y)$ & Probability of $\mathrm{X}$ knowing $\mathrm{Y}$ \\
\hline$f_{X}, f_{Y}, f_{Z}$ & Probability density function of $\mathrm{X}, \mathrm{Y}$ and $\mathrm{Z}$ \\
\hline$F_{X}, F_{Y}, F_{Z}$ & Cumulative density function of $\mathrm{X}$ and $\mathrm{Y}$ \\
\hline$C_{\rho}$ & Gaussian copula \\
\hline$\rho$ & Linear correlation coefficient between two components \\
\hline$\varphi$ & Cumulative density function of the centered reduced normal law \\
\hline $\mathrm{G}$ & Real CDF \\
\hline $\mathrm{F}$ & Estimated CDF \\
\hline $\mathrm{N}$ & Absolute average error \\
\hline $\mathrm{n}$ & Number of components of $F_{X}$ \\
\hline $\mathrm{m}$ & Number of components of $F_{Y}$ \\
\hline$\alpha(c)$ & Error risk \\
\hline $\mathrm{c}$ & Parameter of the Kolmogorov-Smirnov test \\
\hline$\mu$ & Mean \\
\hline$\sigma$ & Standard deviation \\
\hline
\end{tabular}

\section{Acknowledgements}

This work was supported by the "Enedis Industrial Chair on Smart Grids" research program.

\section{References}

1. Study on the value of flexibility in the management and design basis of distribution networks in France. https://www.cre.fr/en/Documents/Publications/Studies/study-on-thevalue-of-flexibility-in-the-management-and-design-basis-of-distribution-networks-infrance. Accessed January 28, 2019.

2. Repo S, Laaksonen H, Järventausta P. Statistical models of distributed generation for 
distribution network planning. In: CIRED 2005 - 18th International Conference and Exhibition on Electricity Distribution. ; 2005:1-5. doi:10.1049/cp:20051275

3. Kane L, Ault GW. Evaluation of Wind Power Curtailment in Active Network Management Schemes. IEEE Trans Power Syst. 2015;30(2):672-679. doi:10.1109/TPWRS.2014.2336862

4. Keane A, Ochoa LF, Borges CLT, et al. State-of-the-Art Techniques and Challenges Ahead for Distributed Generation Planning and Optimization. IEEE Trans Power Syst. 2013;28(2):1493-1502. doi:10.1109/TPWRS.2012.2214406

5. You S, Bindner HW, Hu J, Douglass PJ. An overview of trends in distribution network planning: A movement towards smart planning. In: 2014 IEEE PES T D Conference and Exposition. ; 2014:1-5. doi:10.1109/TDC.2014.6863446

6. Hemmati R, Hooshmand R-A, Taheri N. Distribution network expansion planning and DG placement in the presence of uncertainties. Int J Electr Power Energy Syst. 2015;73:665-673. doi:10.1016/j.ijepes.2015.05.024

7. Borges CLT, Martins VF. Multistage expansion planning for active distribution networks under demand and Distributed Generation uncertainties. Int J Electr Power Energy Syst. 2012;36(1):107-116. doi:10.1016/j.ijepes.2011.10.031

8. Nassar ME, Salama MMA. Probabilistic power flow using novel wind and solar probabilistic models. In: 2016 IEEE Power and Energy Society General Meeting (PESGM). ; 2016:1-5. doi:10.1109/PESGM.2016.7741568

9. Karimi M, Haghifam MR. Multi-objective Dynamic Planning of Substations and Primary Feeders Considering Uncertainties and Reliability. In: ; 2017.

10. Jupe SCE, Taylor PC, Michiorri A. Coordinated output control of multiple distributed generation schemes. IET Renew Power Gener. 2010;4(3):283. doi:10.1049/ietrpg.2009.0142

11. Fan M, Vittal V, Heydt GT, Ayyanar R. Probabilistic Power Flow Studies for Transmission Systems With Photovoltaic Generation Using Cumulants. IEEE Trans Power Syst. 2012;27(4):2251-2261. doi:10.1109/TPWRS.2012.2190533

12. Faghihi F, Labeau P, Maun J, Vergnol A, Wilde VD. A net balance-based approach in risk assessment of distributed generation curtailment. In: 2015 IEEE Eindhoven PowerTech. ; 2015:1-6. doi:10.1109/PTC.2015.7232768

13. Valizadeh Haghi H, Tavakoli Bina M, Golkar MA, Moghaddas-Tafreshi SM. Using Copulas for analysis of large datasets in renewable distributed generation: PV and wind power integration in Iran. Renew Energy. 2010;35(9):1991-2000. doi:10.1016/j.renene.2010.01.031

14. Ranković A, Maksimović BM, Sarić AT, Lukič U. ANN-based correlation of measurements in micro-grid state estimation. Int Trans Electr Energy Syst. 2015;25(10):2181-2202. doi:10.1002/etep.1956

15. Vidović PM, Sarić AT. A novel correlated intervals-based algorithm for distribution 
power flow calculation. Int $J$ Electr Power Energy Syst. 2017;90:245-255. doi:10.1016/j.ijepes.2016.12.019

16. Torres PJF, Ekonomou L, Karampelas P. The Correlation Between Renewable Generation and Electricity Demand: A Case Study of Portugal. In: Karampelas P, Ekonomou L, eds. Electricity Distribution: Intelligent Solutions for Electricity Transmission and Distribution Networks. Energy Systems. Berlin, Heidelberg: Springer Berlin Heidelberg; 2016:119-151. doi:10.1007/978-3-662-49434-9_5

17. Villanueva D, Feijóo A, Pazos JL. Probabilistic Load Flow Considering Correlation between Generation, Loads and Wind Power. Smart Grid Renew Energy. 2011;02:12. doi:10.4236/sgre.2011.21002

18. De Smith MJ. Statistical Analysis Handbook: A Comprehensive Handbook of Statistical Concepts, Techniques and Software Tools. Dr Michael J de Smith; 2013.

19. Olmo F., Vida J, Foyo I, Castro-Diez Y, Alados-Arboledas L. Prediction of global irradiance on inclined surfaces from horizontal global irradiance. Energy. 1999;24(8):689704. doi:10.1016/S0360-5442(99)00025-0

20. Saporta G. Probabilités, Analyse Des Données et Statistique. Editions Technip; 2006.

21. An Introduction to Copulas | Roger B. Nelsen | Springer. https://www.springer.com/la/book/9780387286594. Accessed January 28, 2019.

22. Embrechts P, Lindskog F, Mcneil A. Modelling Dependence with Copulas and Applications to Risk Management. In: Handbook of Heavy Tailed Distributions in Finance. Elsevier; 2003:329-384. doi:10.1016/B978-044450896-6.50010-8

23. Arrêté Du 31 Juillet 2001 Fixant Les Conditions d'achat de l'électricité Produite Par Les Installations de Cogénération d'électricité et de Chaleur Valorisée Telles Que Visées à l'article 3 Du Décret $N^{\circ}$ 2000-1196 Du 6 Décembre 2000 Fixant Par Catégorie d'installations Les Limites de Puissance Des Installations Pouvant Bénéficier de l'obligation d'achat d'électricité.

24. Brucoli M, Torelli F, Napoli R. Quadratic probabilistic load flow with linearly modelled dispatch. Int J Electr Power Energy Syst. 1985;7(3):138-146. doi:10.1016/01420615(85)90042-0

25. Tarif rachat photovoltaique avec EDF - Les Énergies Renouvelables. EcoInfos. https://www.les-energies-renouvelables.eu/conseils/photovoltaique/tarif-rachatelectricite-photovoltaique/. Accessed January 28, 2019. 